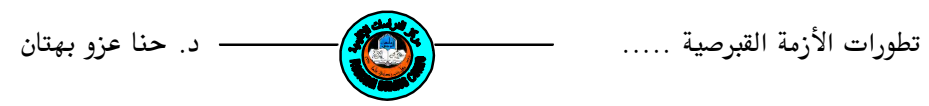

$$
\text { تطورات الأزمة القبرصية (1967-1983) }
$$

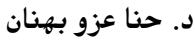

مدرس/ قسم الدراسات التاريخية والثقافية /مركز الدراسات الإقليمية

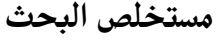

برزت ألازمة القبرصية على المسرح الدولي عقب حصول قبرص على استقلالها سـنة 1960 والـتي

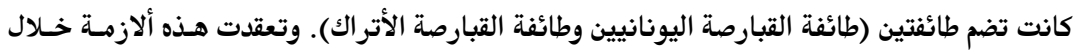

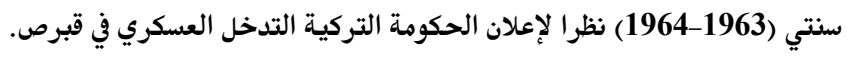

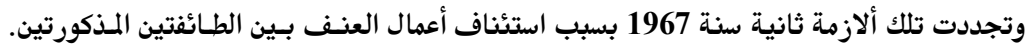

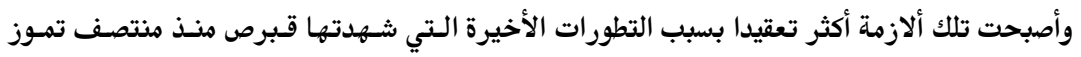

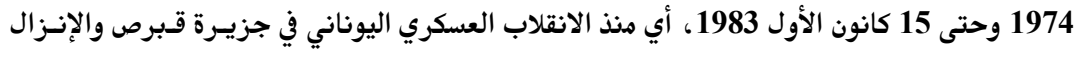

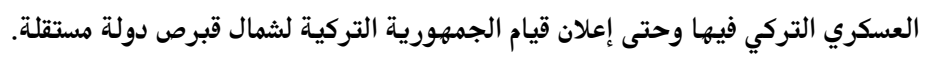

تمهيد

سيطرت الدولة العثمانية على جزيـرة قبرص خـلال الحقبـة (1571-1878) بعـد أن

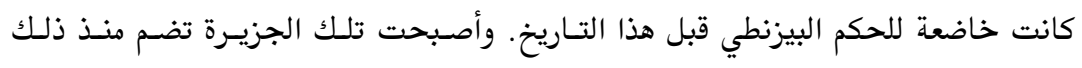

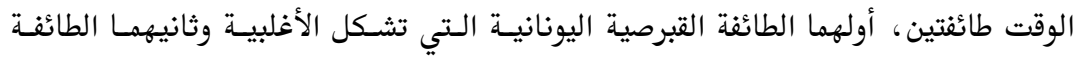

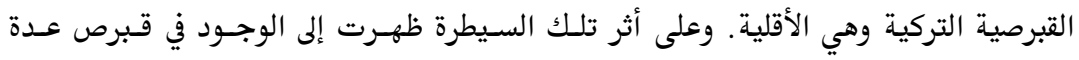

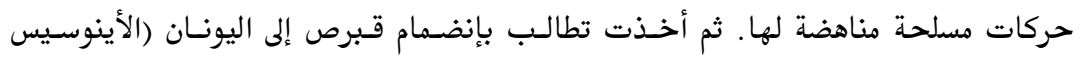

(Enosis

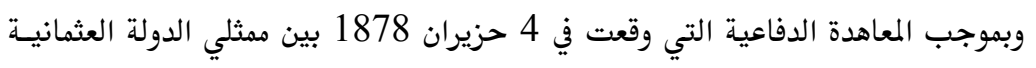
وبريطانيا أصبحت قبرص خاضعة لإدارة الثانية بعد الموقف البريطاني الداعم للدولة العثمانية

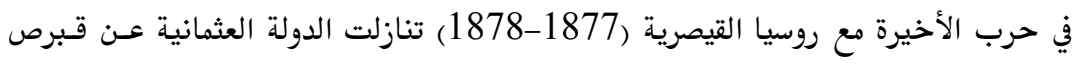

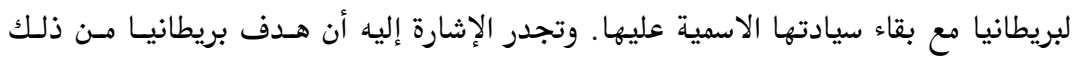


الاتفاق كان السيطرة على تلك الجزيرة ذات الموقع الأستراتيجي لتأمين طرق مواصـلاتها إلى

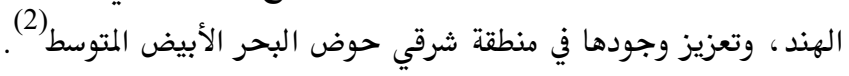

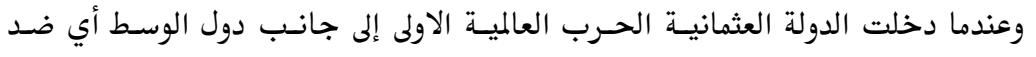

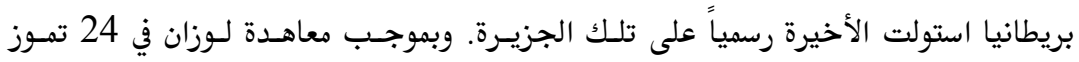

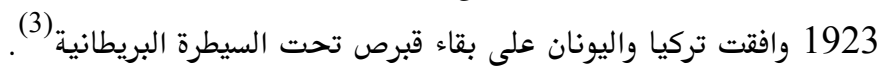

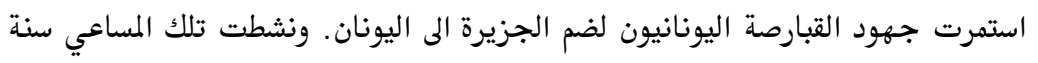

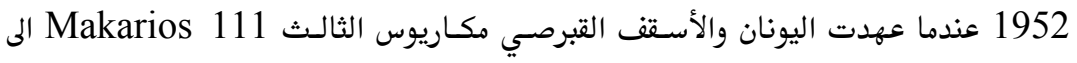

الجنرال جورجيو غريفاس Georgios Grivas- يوناني من أصل قبرصي- مهرمة تشكيل هنظمة مسلحة أطلق عليها أسم إيوكا E. O. K. A (المذظمة القومية للمقـاتلين القبارصـة) ،

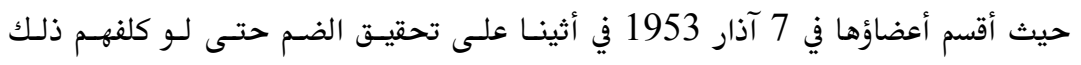

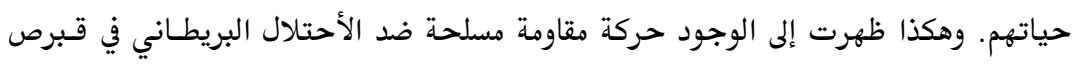

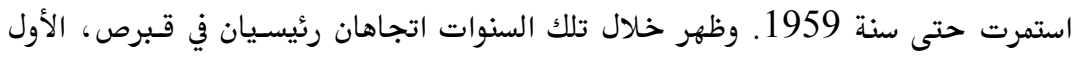

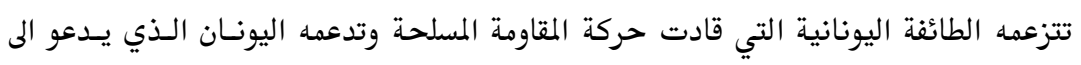

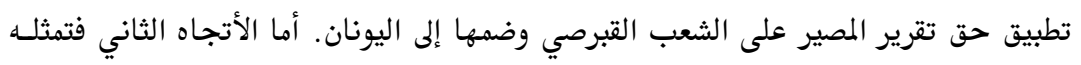

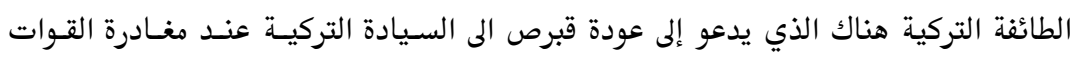

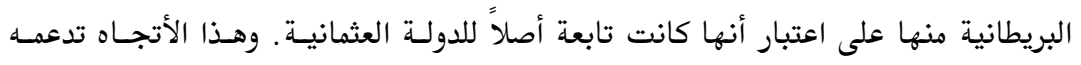

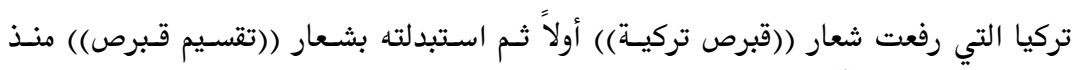
أواخر سنة 1956 (4) وفي أوائل سنة 1959 جرت عدة مشـاورات بـين المسؤولين الأتـراك واليونسانيين بشـأن

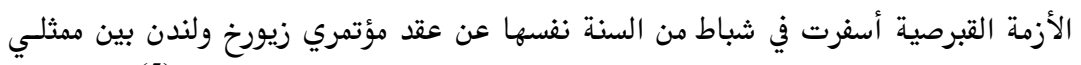

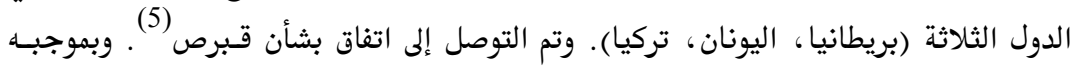

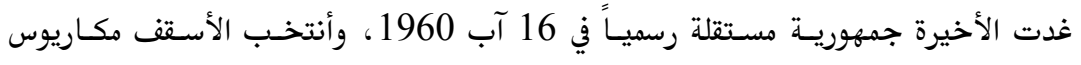

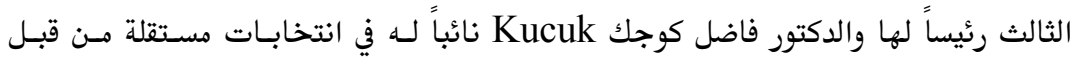

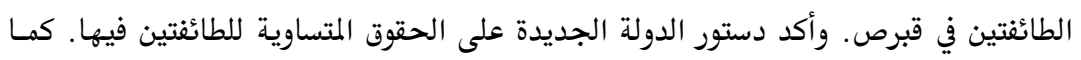




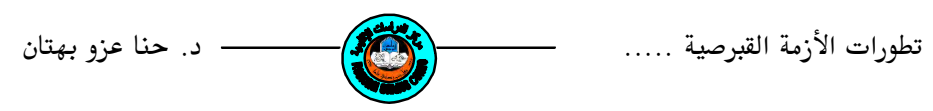

عقدت في اليوم نفسه معاهدتي الضمان والتحالف طبقاً لاتفاقية لندن. وأكدت معاهدة الضمان

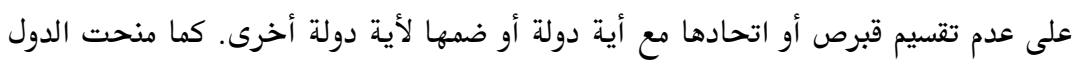
الضامنة الثلاث حق التدخل في قبرص للدحافظة على تلى تلك المعاهدة. وأصبح لتركيـا واليونسان

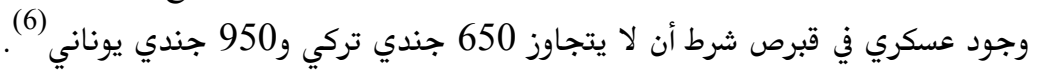

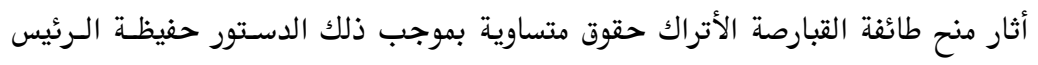

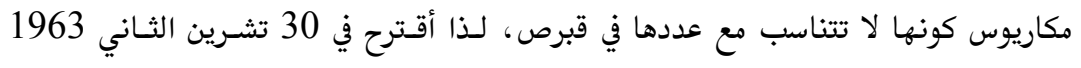

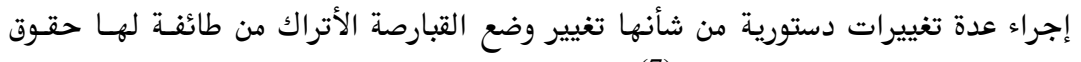

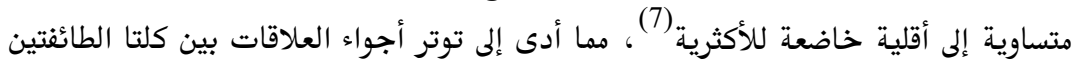

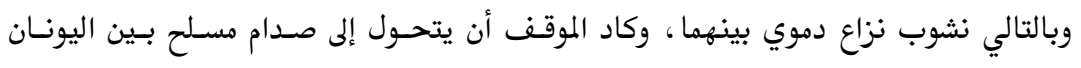

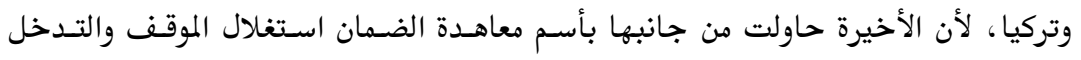

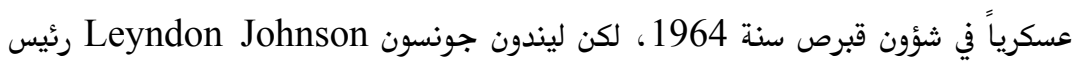

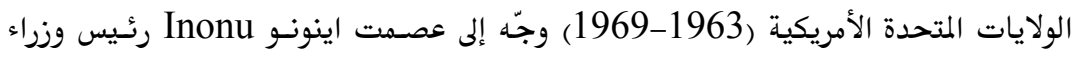

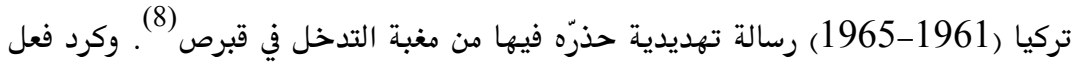

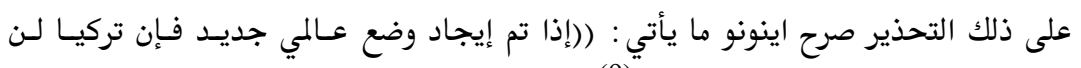

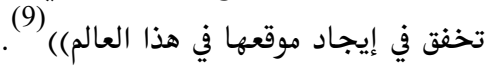
ولهذه الأسباب مجتمعة حولت تركيا ذلك النزاع إلى مذظمة الأمم المتحـدة. وعلى الـرغم

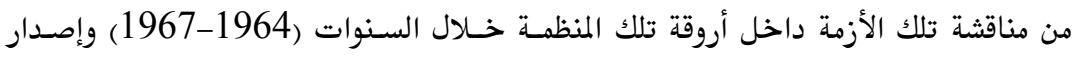

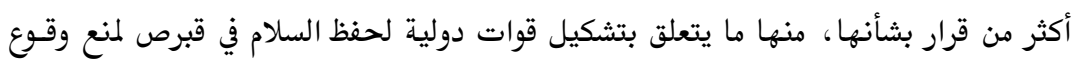

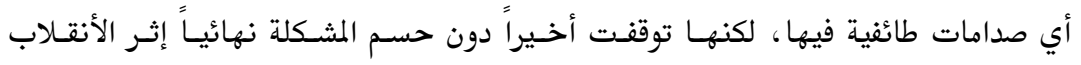

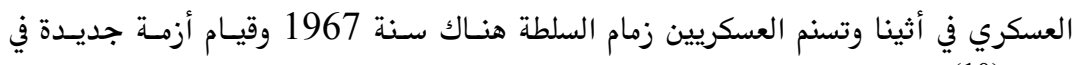


نشأت هذه الأزمة إثر تجدد أعمال العنف ثانية في 15 تشرين الثاني 1967 بين قوات

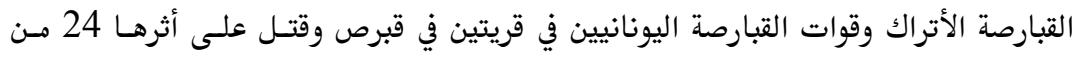

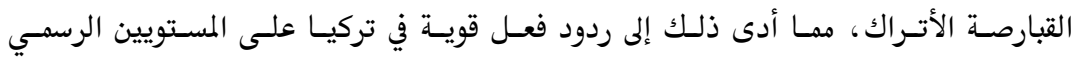

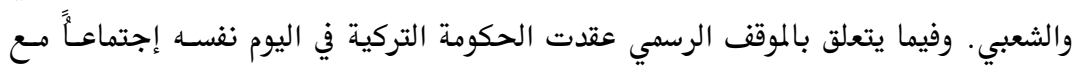

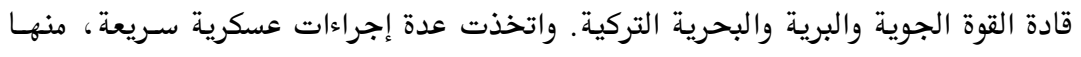

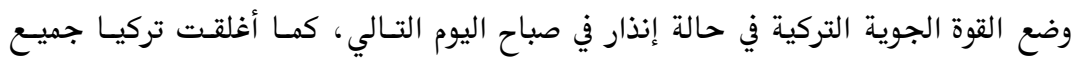

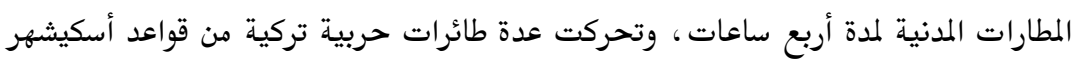
Eskisehir Adana القوات العسكرية التركية في حالة تأهب للانطلاق من المنساطق السـاحلية التركيـة في مرسين التردين -Mersin

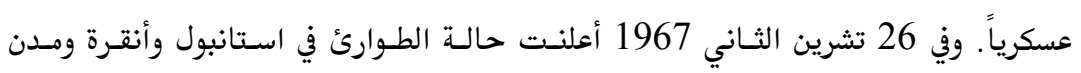

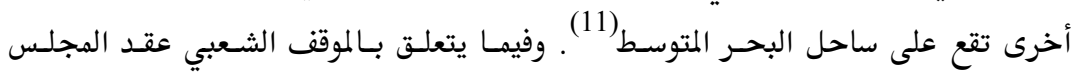

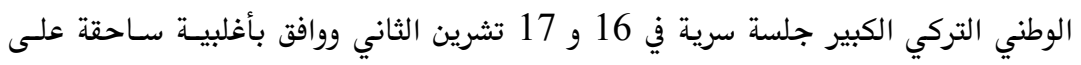

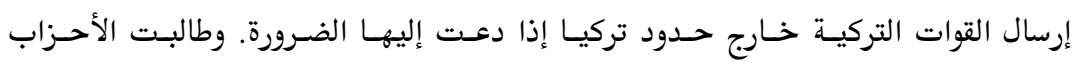

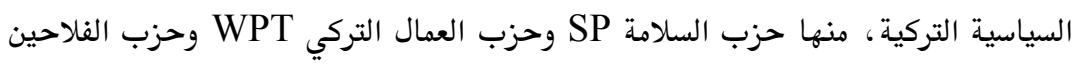

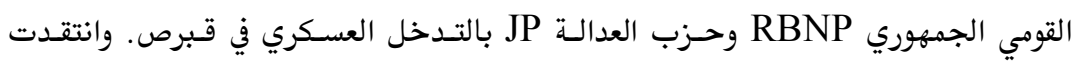

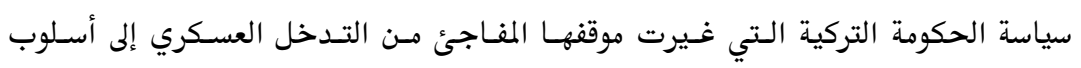

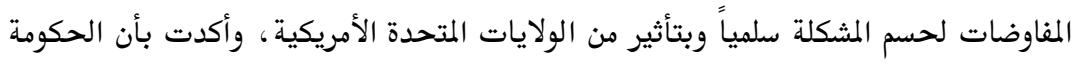

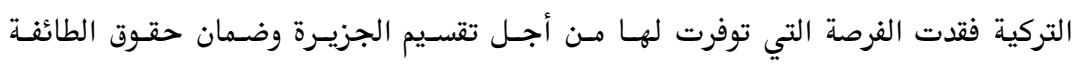

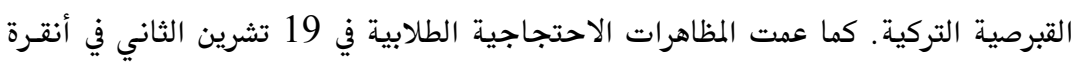

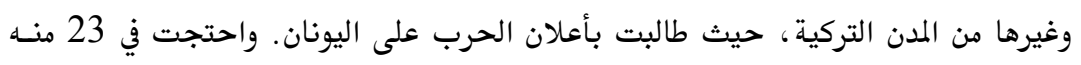
على زيارة سايروس فانس Cyrus Vance المبعوث الخاص للرئيس الأمريكي جونسون إلى الى لقديث

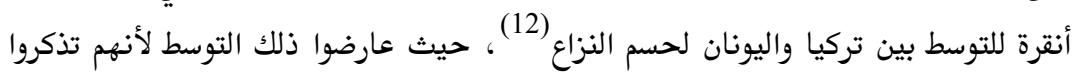


الرسالة التحذيرية التي بعث بها جونسون إلى اينونو سنة 1964 بشأن التدخل في قبرص،

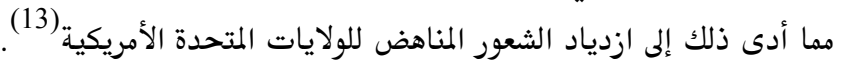
إن الضمانات التي أعطيت للحكومة التركية من قبل نظيرتها اليونانية والمتمثلة باستدعاء المداء الجنرال كريفاس، وسحب القوات العسكرية اليونانية المرابطة في قبرص منذ سنة 1964 إلى لى

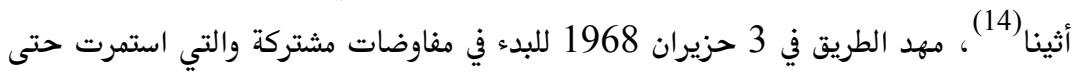

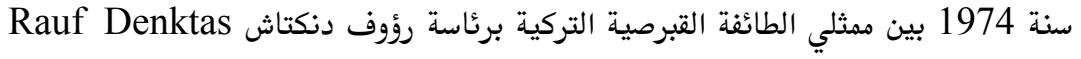

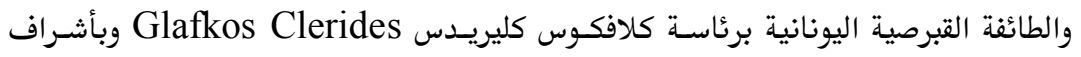
أوسوريو تافال B. F. Osorio Tafall الممثل الخاص للأمين العام للأمم المتحدة، علماً بأن تلك المفاوضات كانت تجري على نحو متقطع بسبب التطورات الجديدة اللاحقة ، فني 20

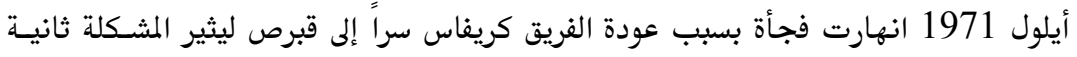

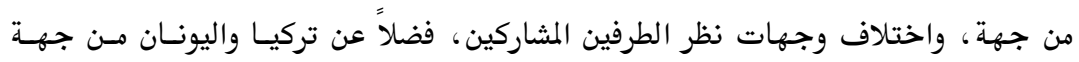
أخرى (15) من جنة. اسـتأنفت تلـك المباحثــات ثانيـة في 8 حزيسـران 1972 وصسرح دنكتــاش في الجلســة

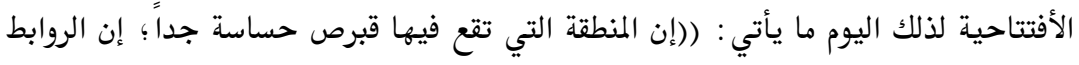

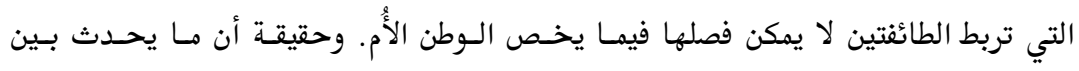

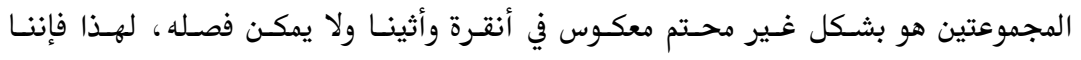

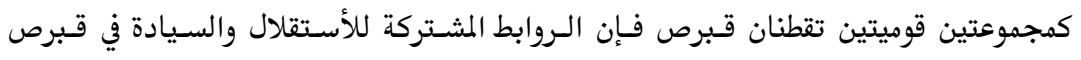

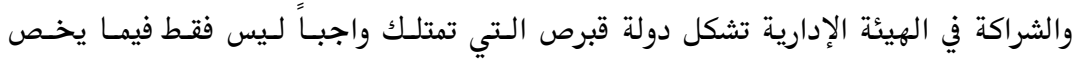

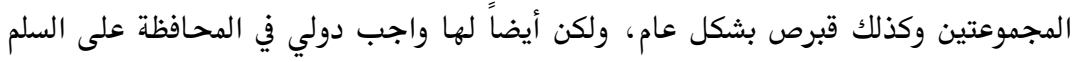
في تلك المنطقة الحساسة...)( (16). توصل الطرفان من خلال تلك المباحثـات الى اتفاقيسة بشـأن السـلطة التشـيعية والحكومسة

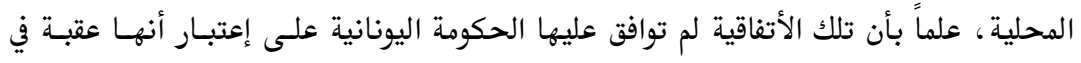

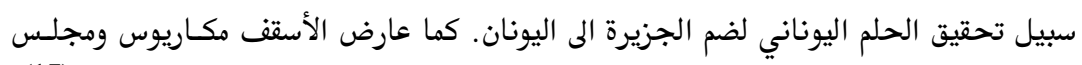

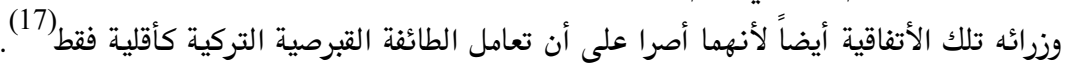

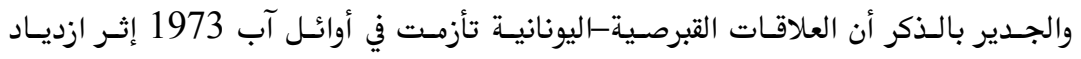




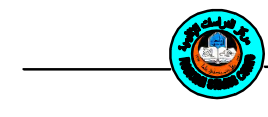

نشاطات منظمة أيوكا السرية في قبرص ، مما حدا بمكاريوس الى تقديم طلب رسمي في 4 تمسوز 1974 الى السلطة العسكرية في اليونان الذي تضمن سحب جميع الضباط اليونانيين العاملين في

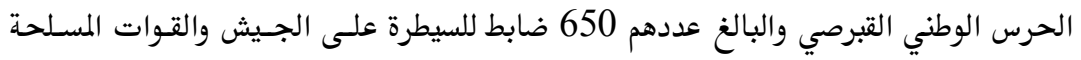

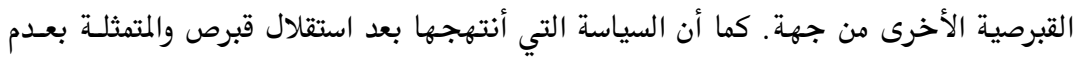

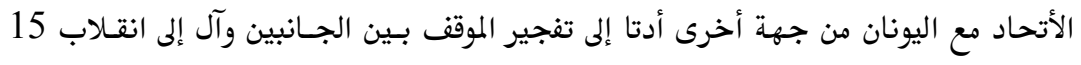

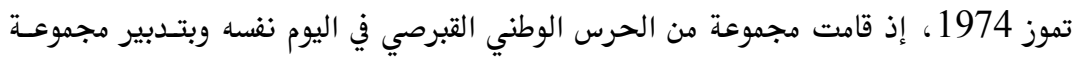

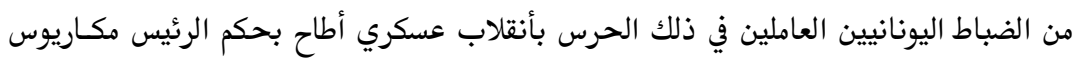

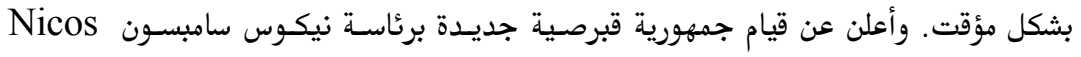

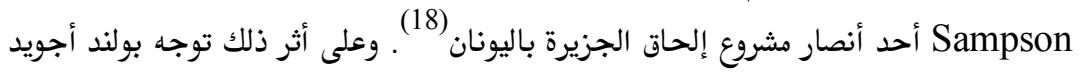
Bulent Ecevit

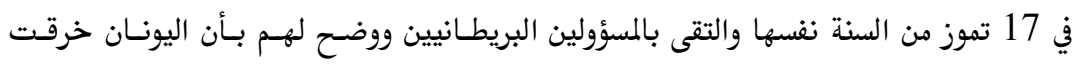

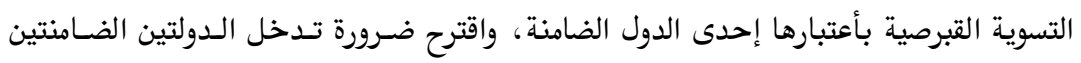

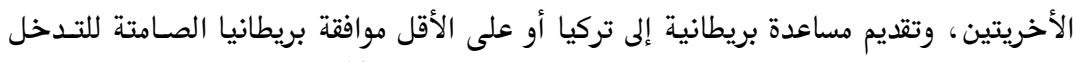

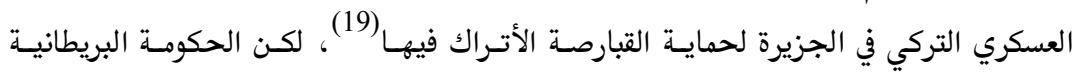

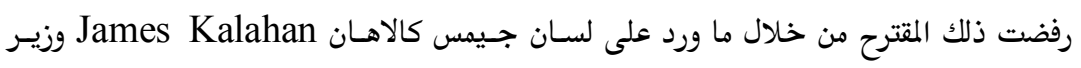

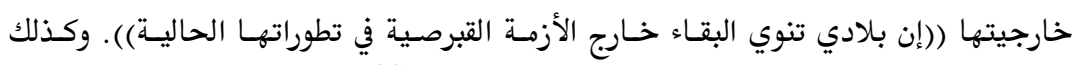
فشلت المساعي الأمريكية لعدول الحكومة التركية عن رأيها (20). الغزو التركي لقبرص سنة 1974 والموقف الدولي منه لـنه وجهــت حكومـة أجويسد في 19 تمهوز 1974 إنـذاراً بالتـدخل إذا لم تنفـذ مطاليبهـا في

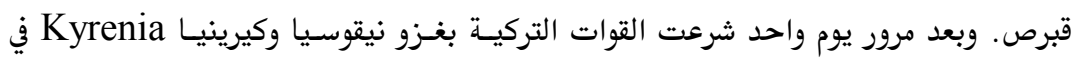

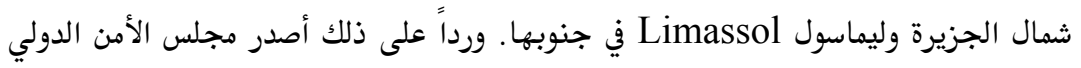

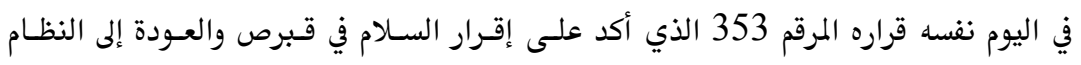

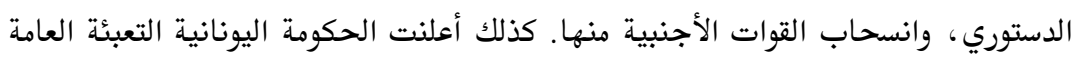

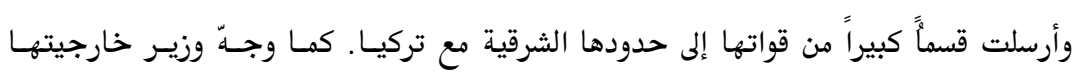




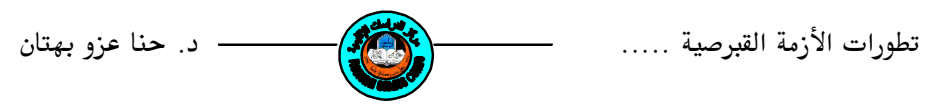

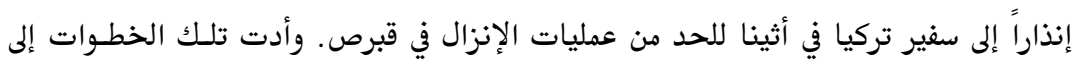

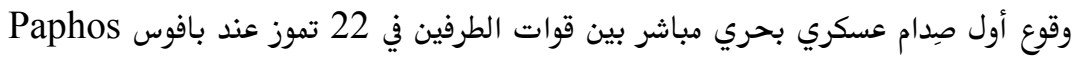

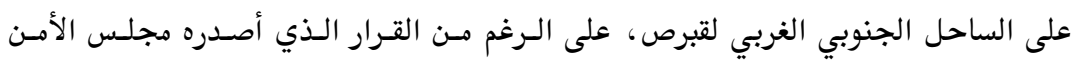

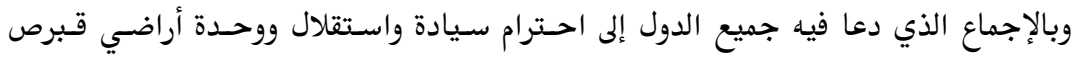

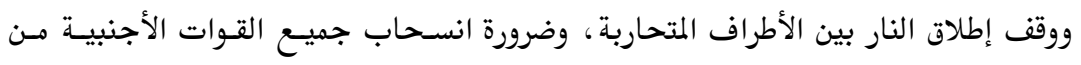

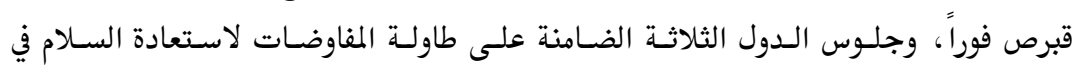

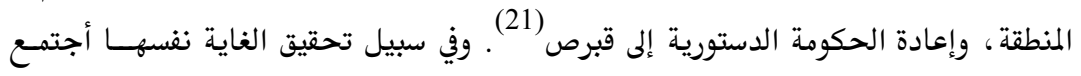

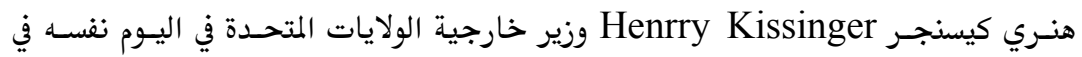
جنيف مع كل من رئيس وزراء تركيا واليونان. وتم التوصل إلى وقف إطلاق النار حسالاً (22).

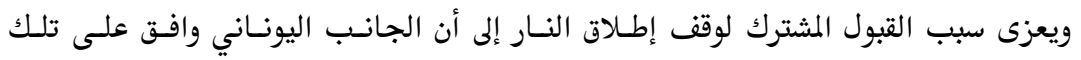

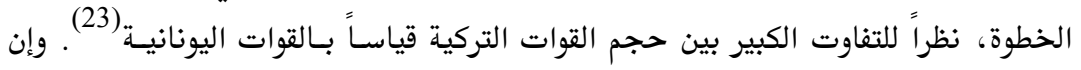

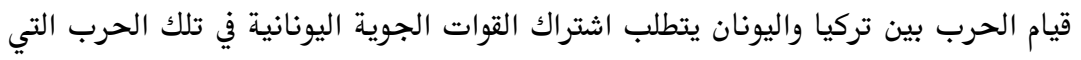

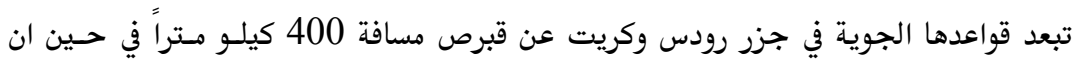

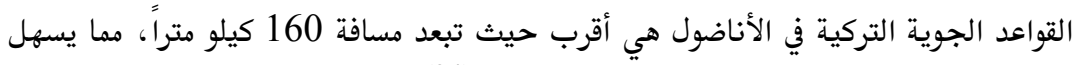

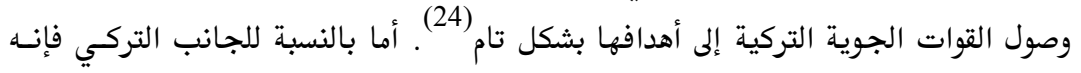

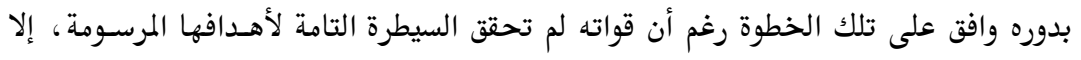

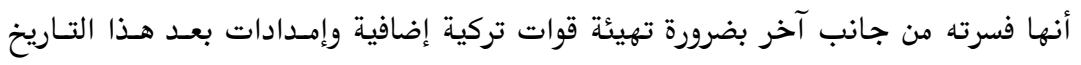

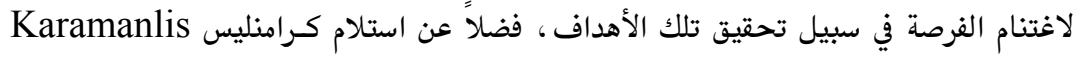

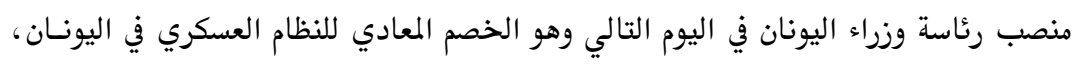

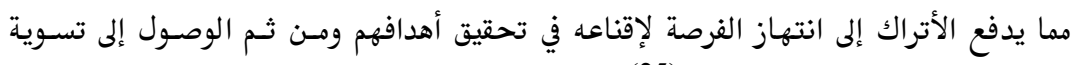

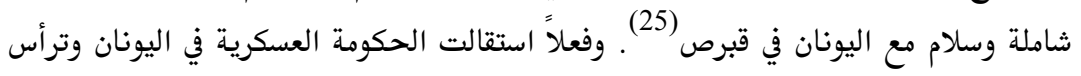

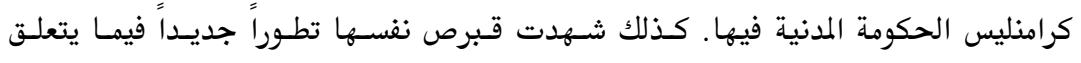

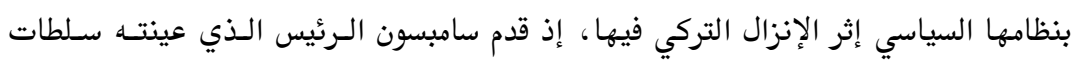

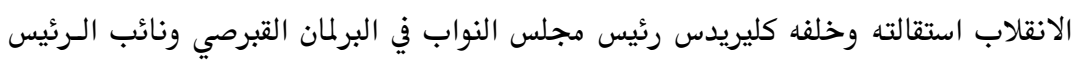

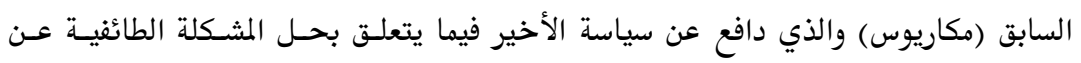


طريق المفاوضات المباشرة بهدف استقلال قبرص كدولة ذات سيادة مع احسترام حقـوق أقليـة

القبارصة الأتراك (26).

هـهدت تلك التطورات السياسية في كل مـن اليونـان وقبرص الطريـق إلى عقد مـؤتمر في

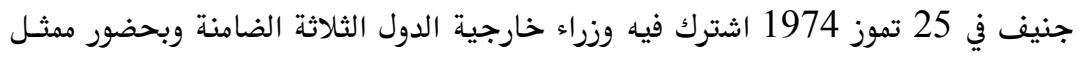

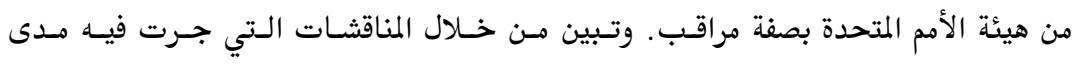

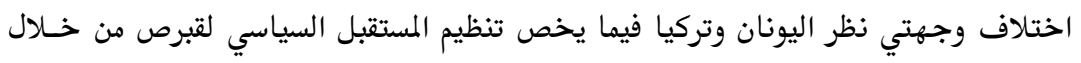

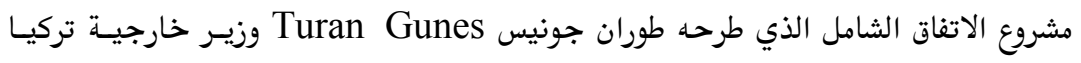

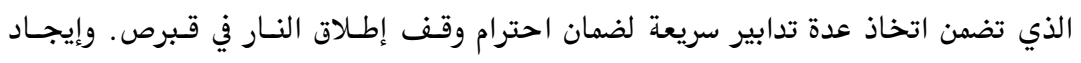

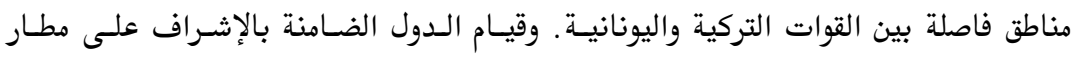

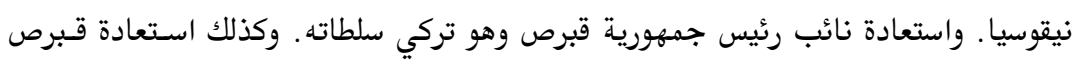

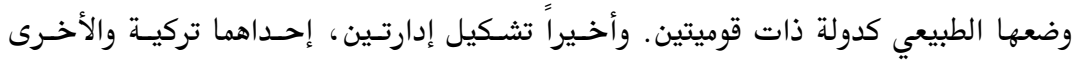

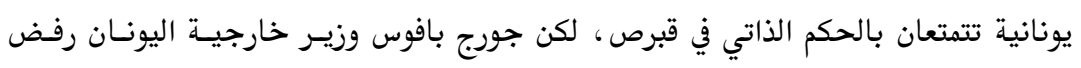

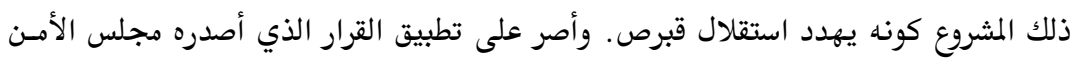

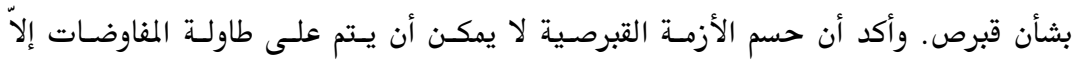

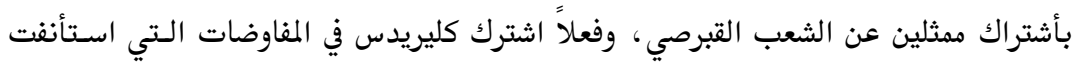

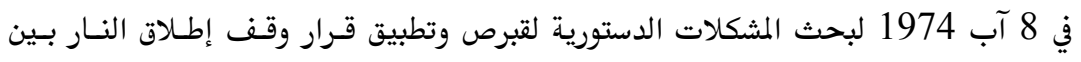

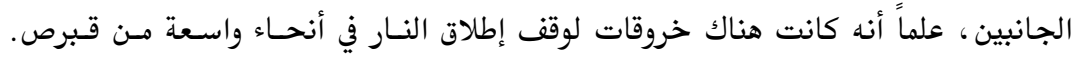

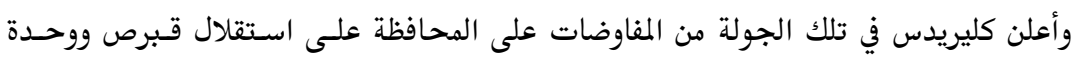

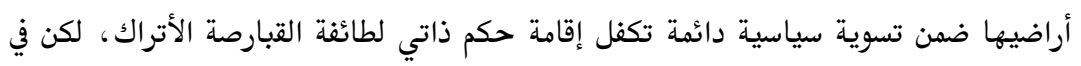

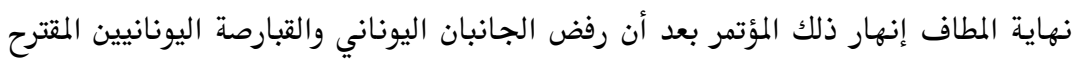

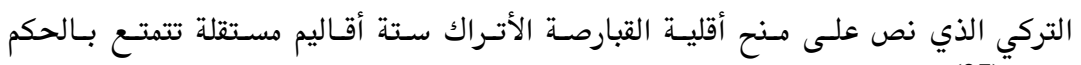

وبسبب عدم إمتثال ممثلي اليونان والقبارصة اليونسانيين لـذلك المقترح إنفجـرت الأزمسة

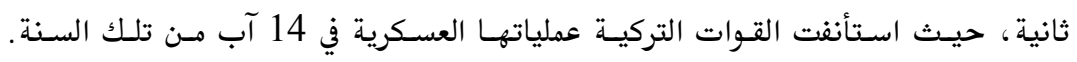




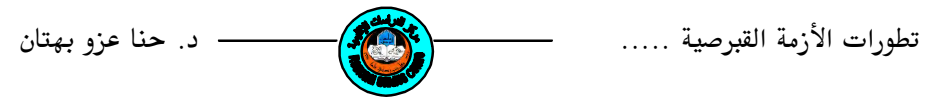
واستطاعت بعد مرور ثلاثة أيام السيطرة على 40٪ من المساحة الكلية لقبرص شمالي الخـط

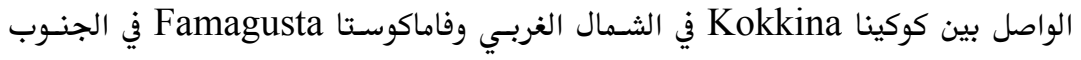

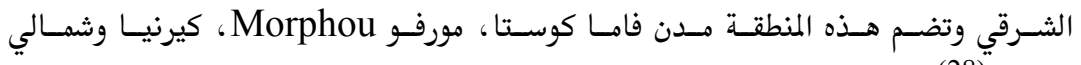

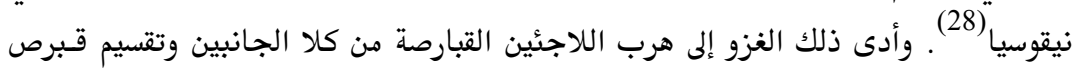

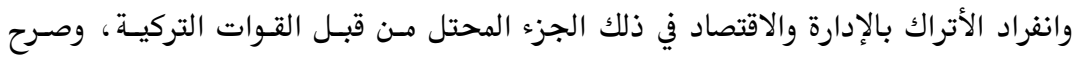

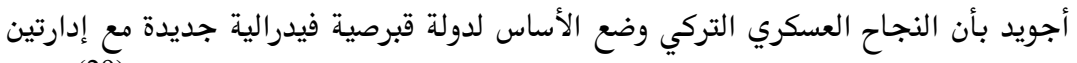

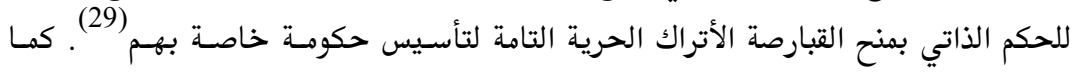
أعلنت تركيا وقف إطلاق النار في قبرص بعد أن حققت أهدافها الأساسية من عملية الإنـزال

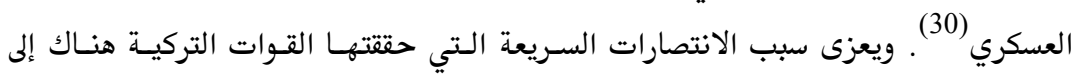

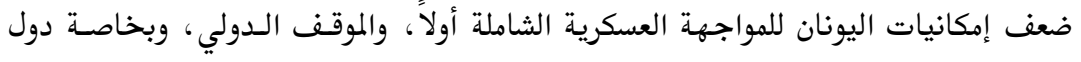

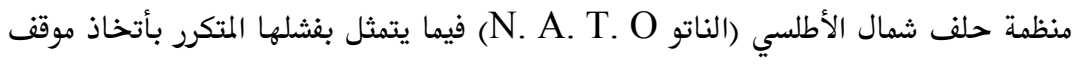

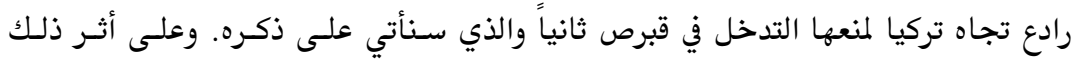

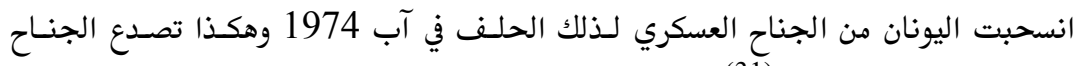

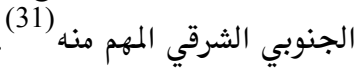
عدّ الأتراك ذلك الغزو لأول وهلة مكسباً وطنياً. كما تيقنوا بأن حصر الطائفـة القبرصية

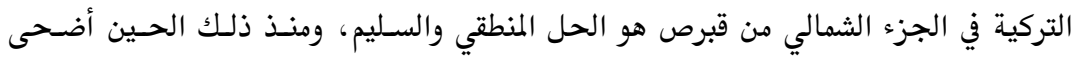

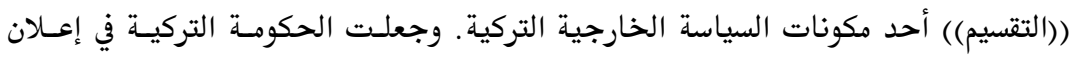
دولة فدرالية للطائفتين الشرط الأساسي لتقليص عدد قواتهـا العسكرية المرابطـة هنـاك (32).

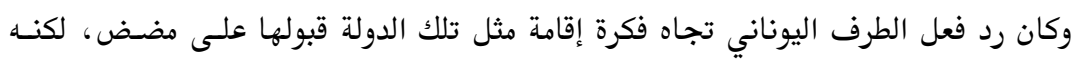

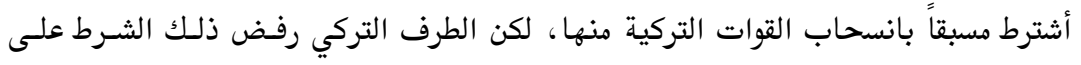

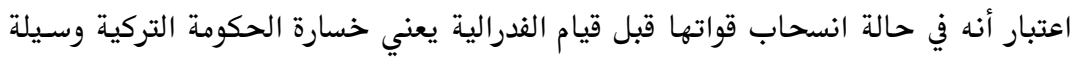

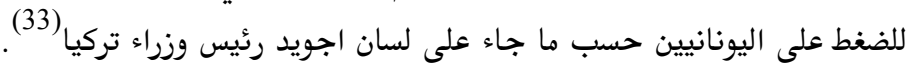

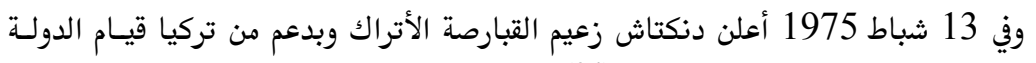

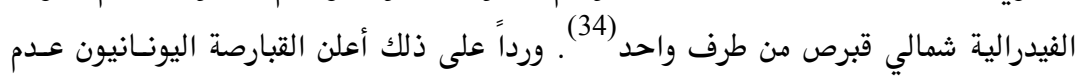

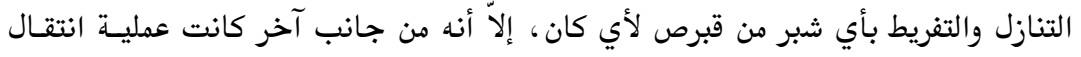


السكان لكـلا الجـانبين تجـري على أرض قـبرص ليرتسـم بــلك ((الخـط الأخضر)) بـين

وفيما يتعلق بموقف دول حلف شمهال الأطلسي والأتحساد السـوفيتي تجـاه التطورات

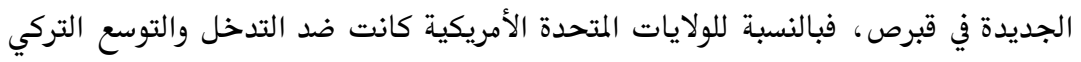

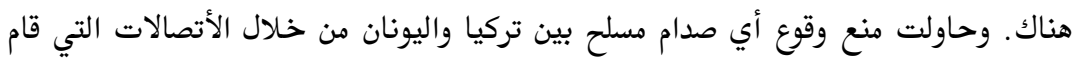

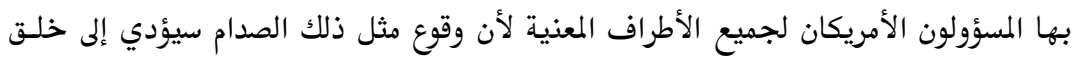

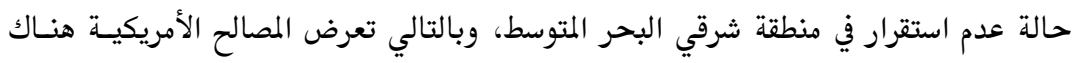

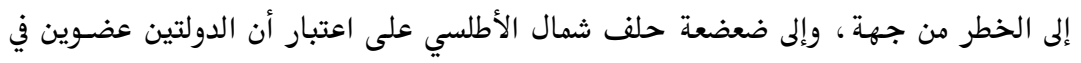

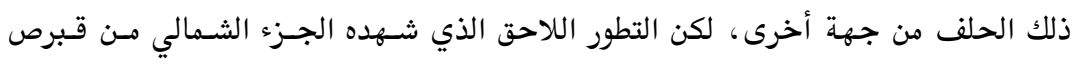

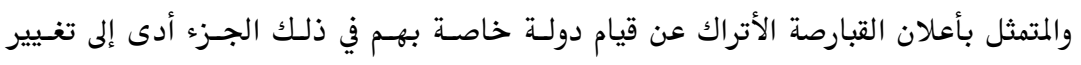

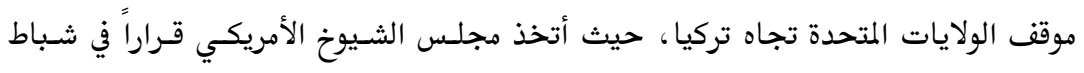

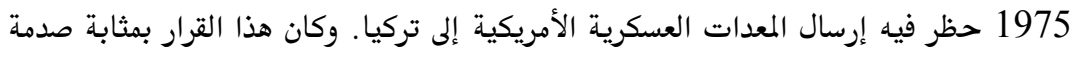

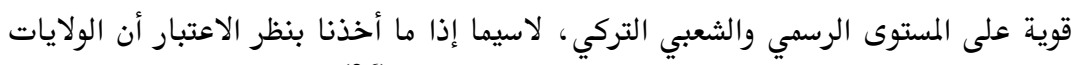

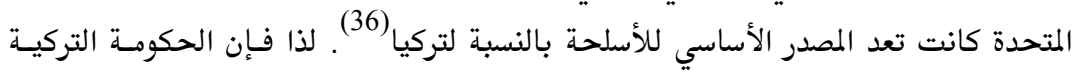

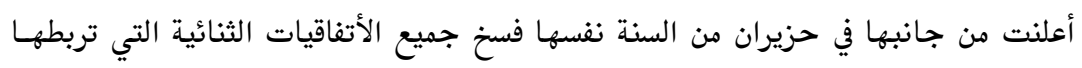

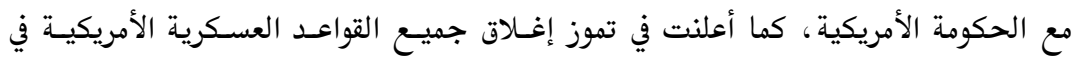

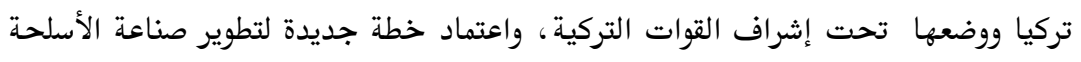

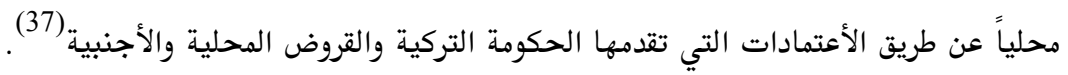

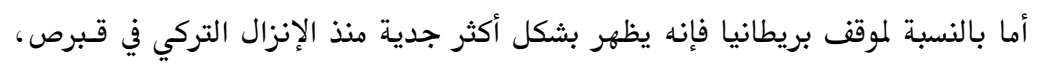

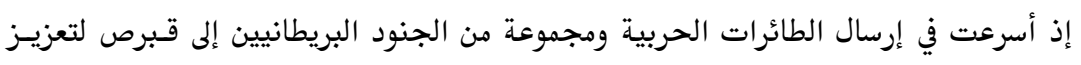

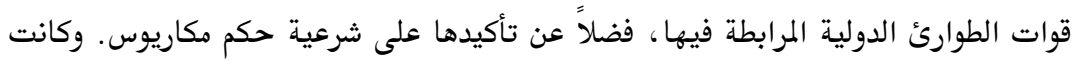

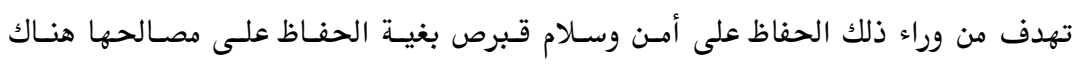

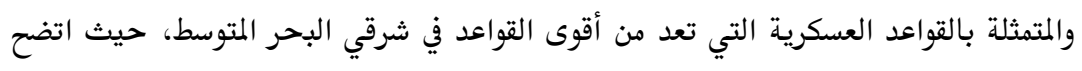
دور تلك القواعد بشكل جلي- بعد حصول دول منطقة شرقي البحر المتوسط على استقلالها- 
لسد حاجة الدول الأوربية من النفط. لذا أصبحت قبرص بعد أن فقدت بريطانيا مصالحها في تلك المنطقة بمثابة مركز قوة لها ضد تلك الدول. وهكذا حاولت بريطانيا منذ استقلال قبرص

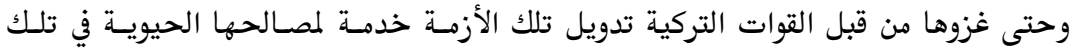

وفيما يتعلق بموقف فرنسا من ذلك الغزو، فلم يكن مؤيداً لذلك الأجراء، ويتضح ذلك من

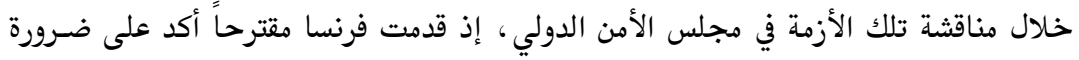

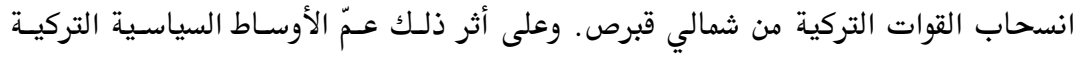

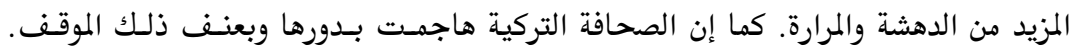

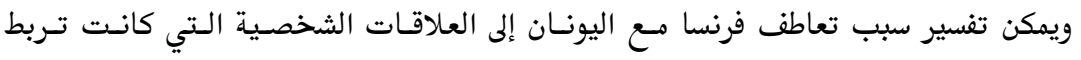

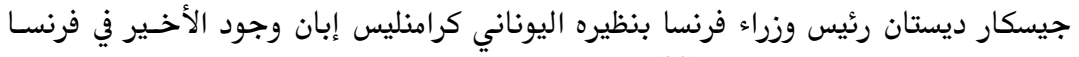

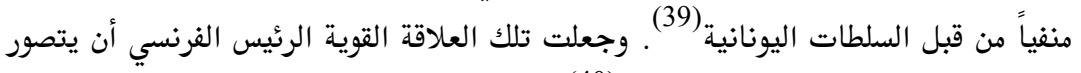

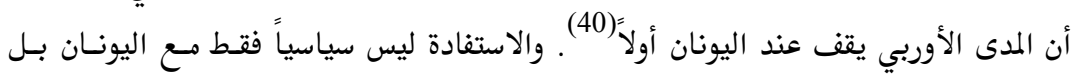

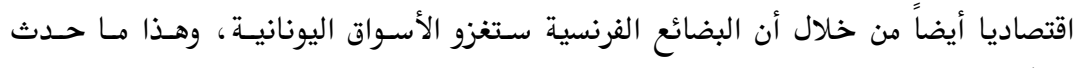

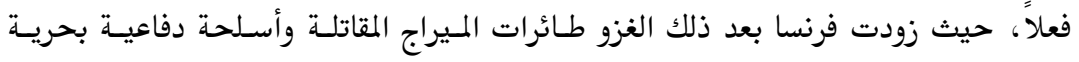

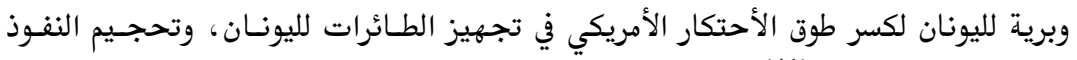
الأمريكي في أوربا ثانياً (41).

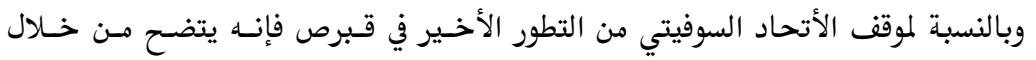

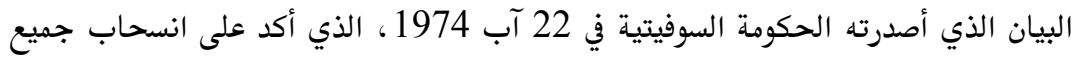

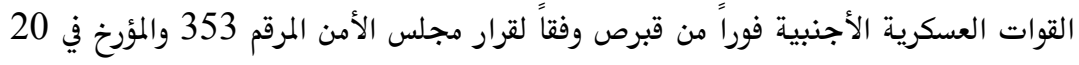

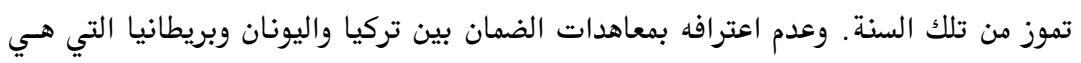

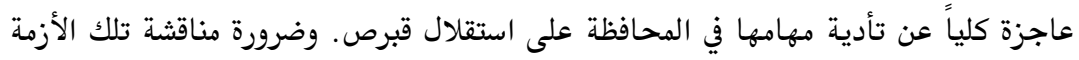

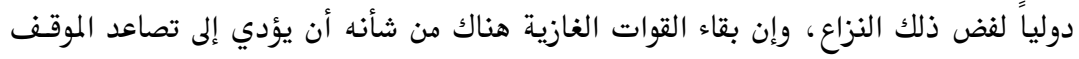
وتوتر العلاقات بين الدول الكبرى مستقبلاً (42)

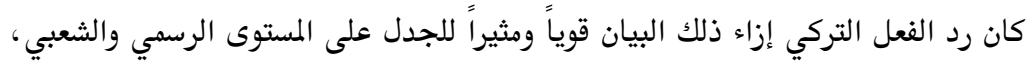

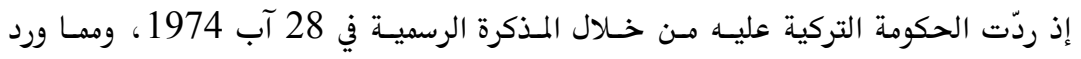


فيها : (أن الدول الضامنة للمعاهدة هي المسؤولة عن احترام سيادة قبرص واستقلالها التـام

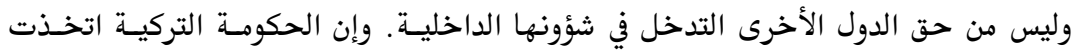

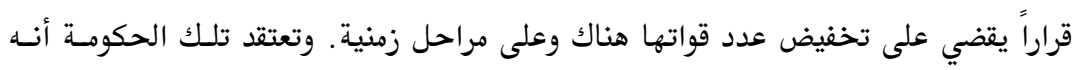

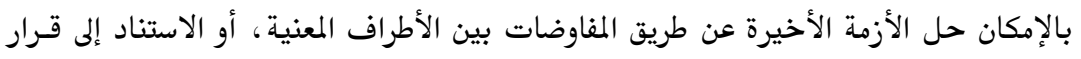

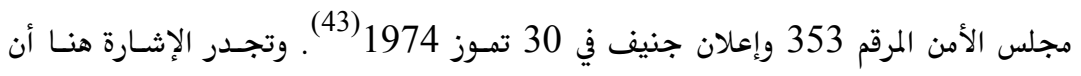

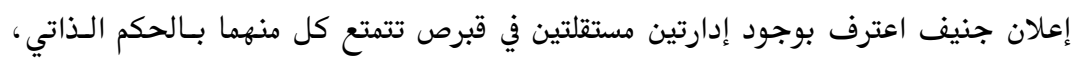

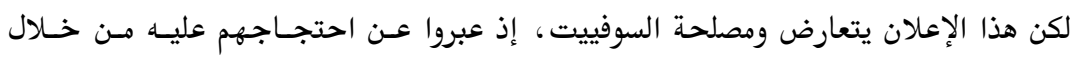
الزيارة التي قام بها رئيس المجلس الوطني التركي الكبير مع عدد من أعضائه إلى موسكو في

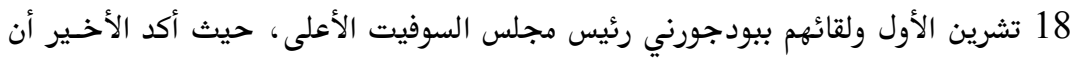

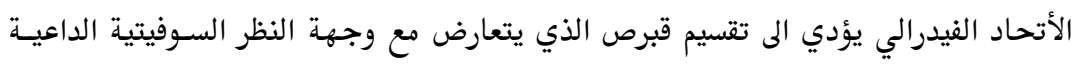

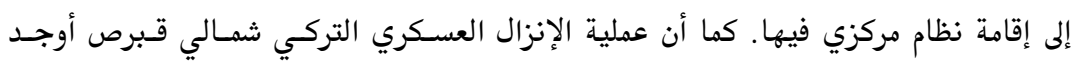

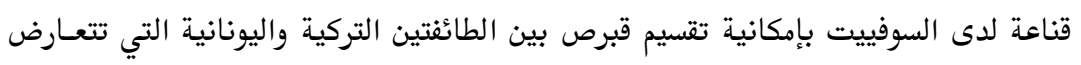

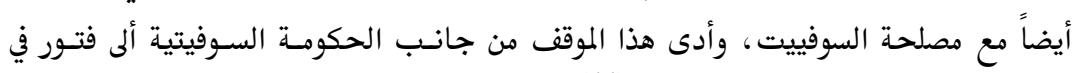
العلاقات بين تركيا والاتحاد السوفيتي (44).

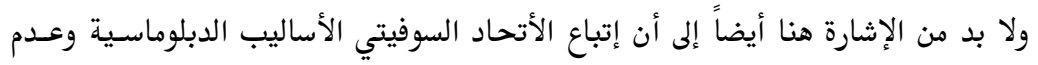

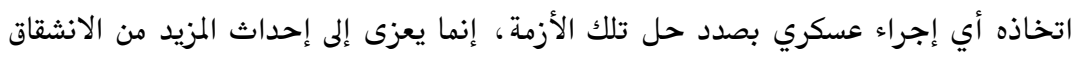

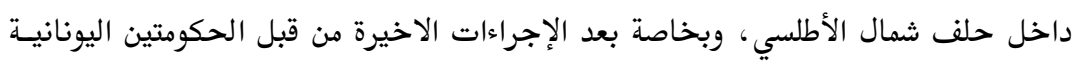

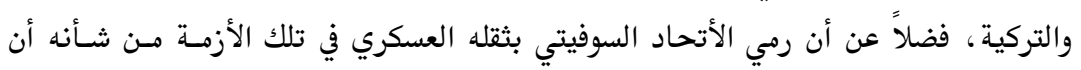

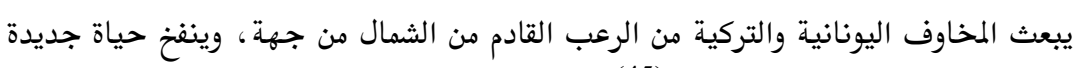
في التحالف الغربي من جهة أخرى (45).

استئناف المفاوضات بشأن الازمة القبرصية(بعد الغزو التركي وحتى اعلان الجمهورية القبرصية التركية) 
جرت عدة لقـاءات ثنائيسة بـين المسؤولين الأتــراك واليونـانيين بشـأن تطـورات الأزمسة القبرصية بعد الغزو التركي لشمالي قبرص. ففي 5 أيار 1975 عقد وزيسر خارجيسة اليونسان

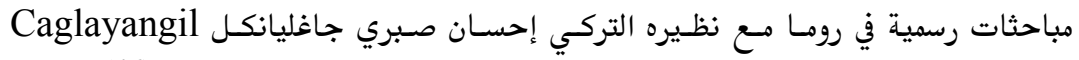

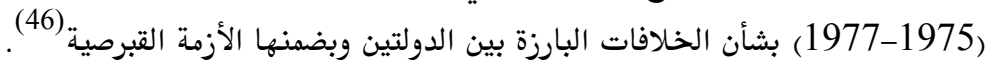
وفي أواخر 1976 التقى الاثنان في نيويورك للتباحث بشأن تلك الأزمة وعلى قدم المساواة

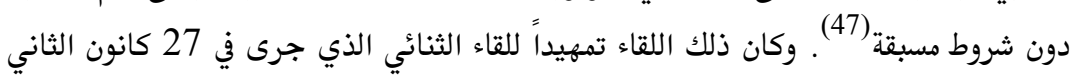

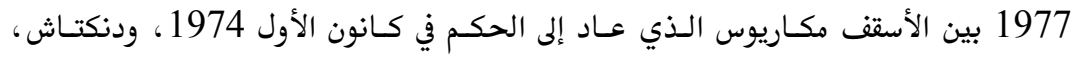
وأعقبه لقاءً آخر في 12 شباط 1977 وبأشراف كورت فالدهايم الأمين العام للأمسم المتحسدة،

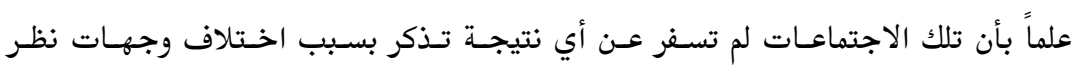
الأطراف المشاركة (48).

وفي نيسان من تلك السنة عقد اجتماع آخر بين ممثلي الطائفتين في فيينا وقدم سـبيروس

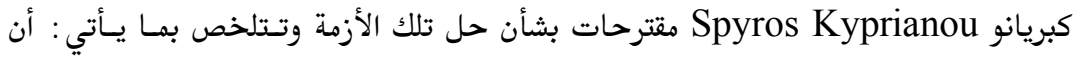
يتولى القبارصة الأتراك إدارة 20٪ من مساحة قبرص وهي نسبة تعادل حجم طائفة القبارصة

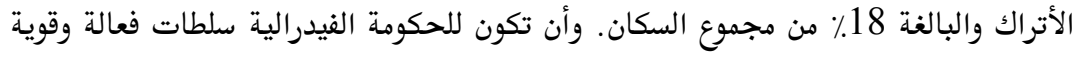

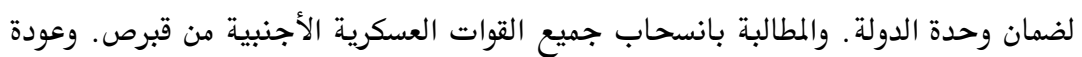
200 ألف لاجيء قبرصي يوناني إلى ديارهم (49). وبعد وفاة مكاريوس في 3 آب 1977 خلفه كبريانو الذي أخذ على ئلى عاتقه مهمة استئناف

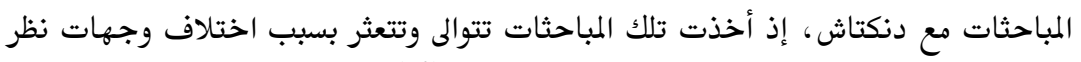
الطرفين فيما يتعلق بالشؤون المحلية والإقليمية لقبرص (50).

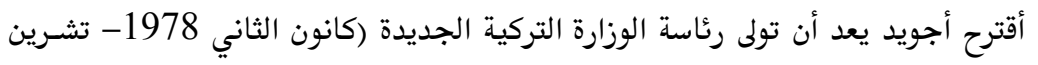

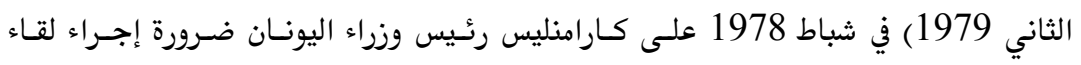

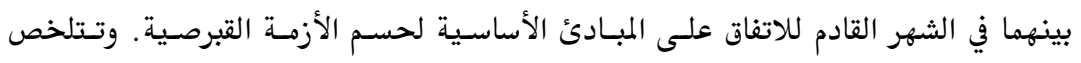

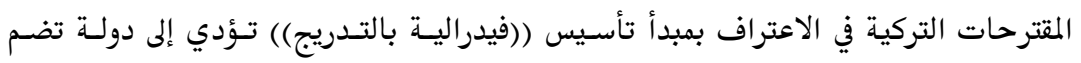

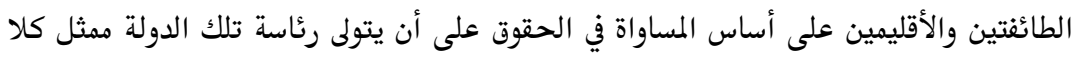

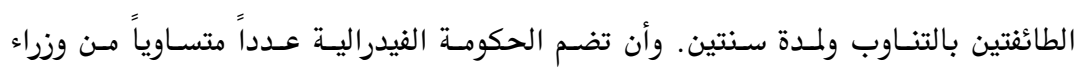




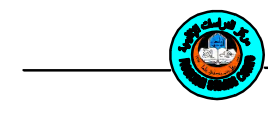

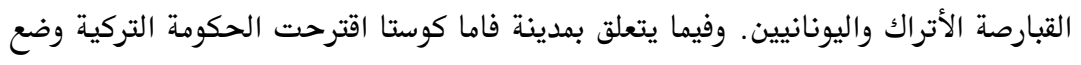

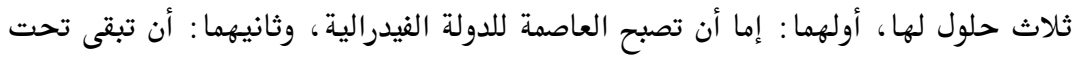

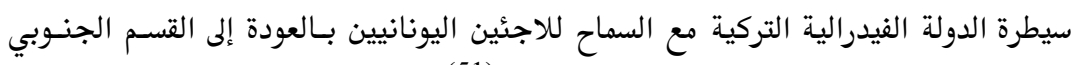
من قبرص، وثالثهما : تقسيم المدينة بين الطائنتين (51).

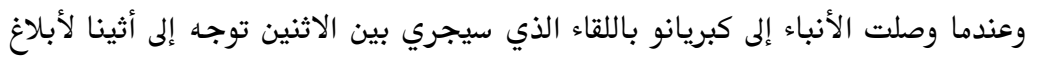

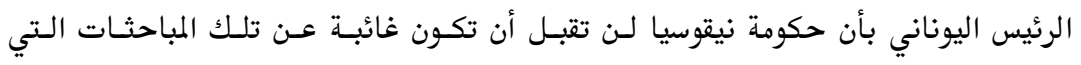

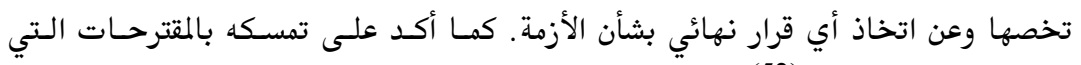

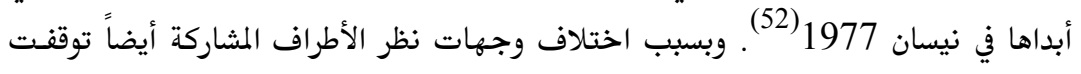

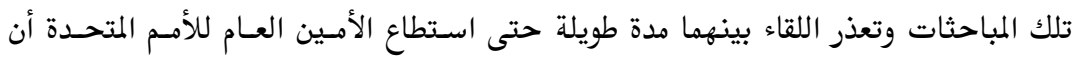

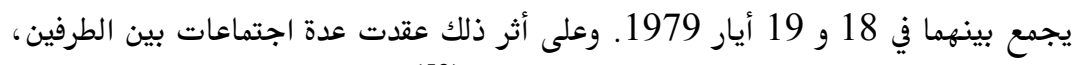
لكنها فشلت أيضاً في التوصل إلى حل يرضي الطرفين (53).

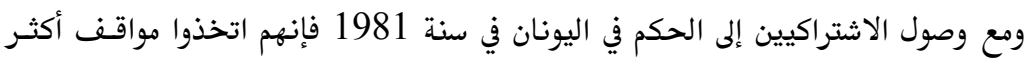

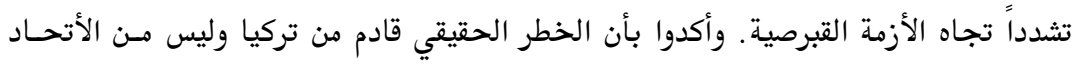

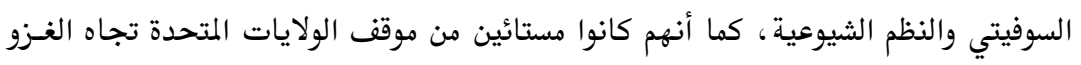

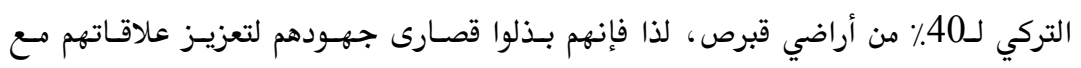
الأتحاد السوفيتي ودول حلف وارشو للفي للفيط على الولايات المتحدة وحلف شمال الأطلسي في

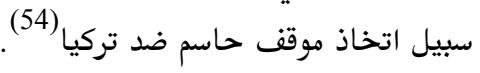
وعلى أثر الإخفاقات المتكررة لتلك المباحثات والموقف المتغير للحكومة الجديدة في اليونان أقدم دنكتاش في 15 كانون الأول 1983 على خطوة إعلان قيام الجمهورية التركيـة لشـمال

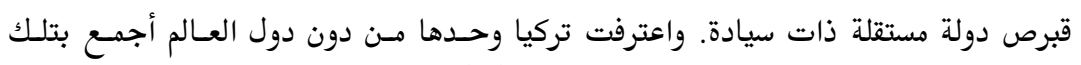
الدولة الجديدة، وشرعت تدعمها اقتصاديا ومالياً(55). 


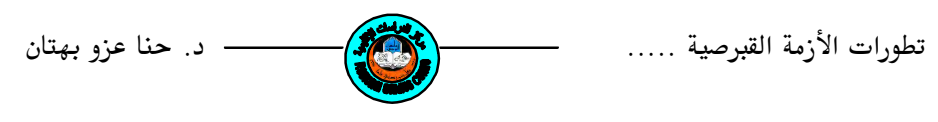

تعود الجذور التاريخية للأزمة القبرصية منـذ أن سيطرت الدولـة العثمانيسة على تلك

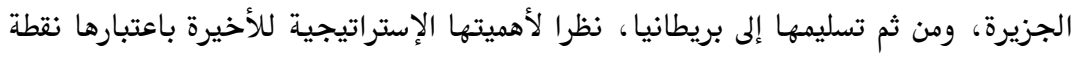

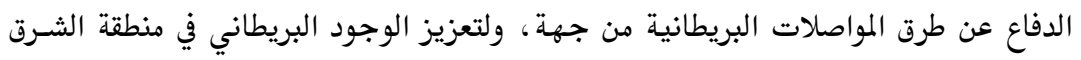

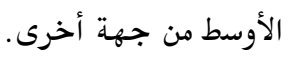

برزت تلك الأزمة على المسرح الدولي عقب حصول قبرص على اسـتقلالها سـنة 1960

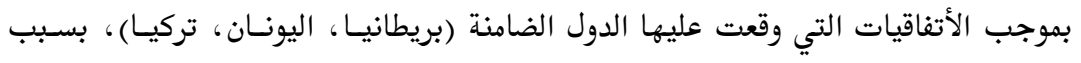

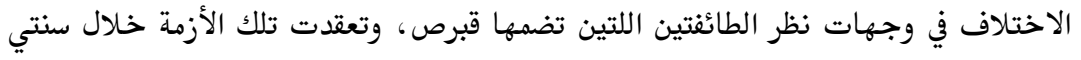

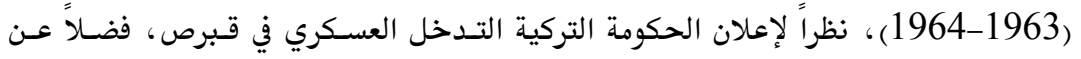

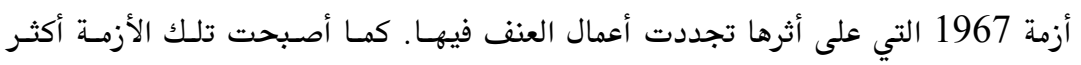

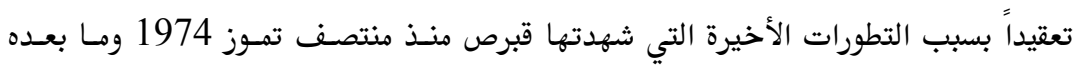

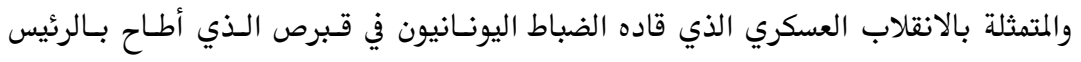

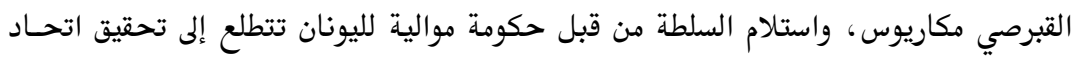

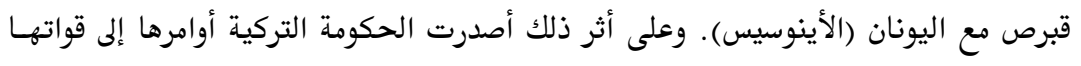

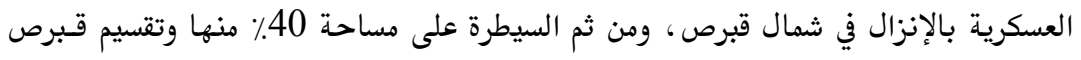

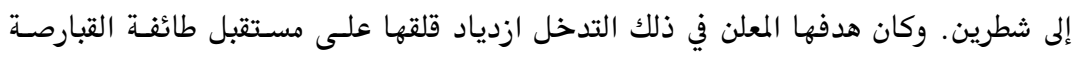

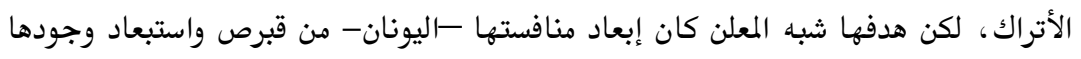

$$
\text { العسكري هناك. }
$$

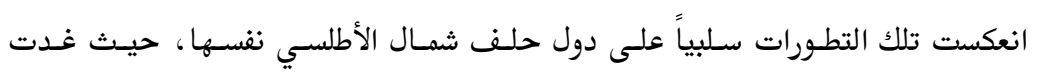

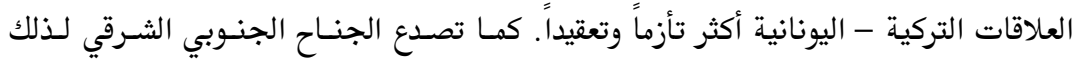

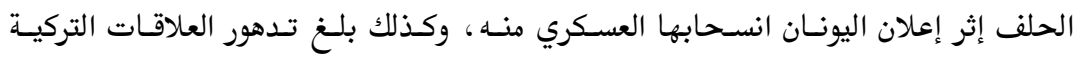

$$
\text { الأمريكية ذروته عقب ذلك الغزو. }
$$

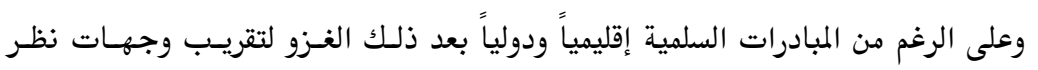
الأطراف المتصارعة، لكنها أخفقت جميعها. 


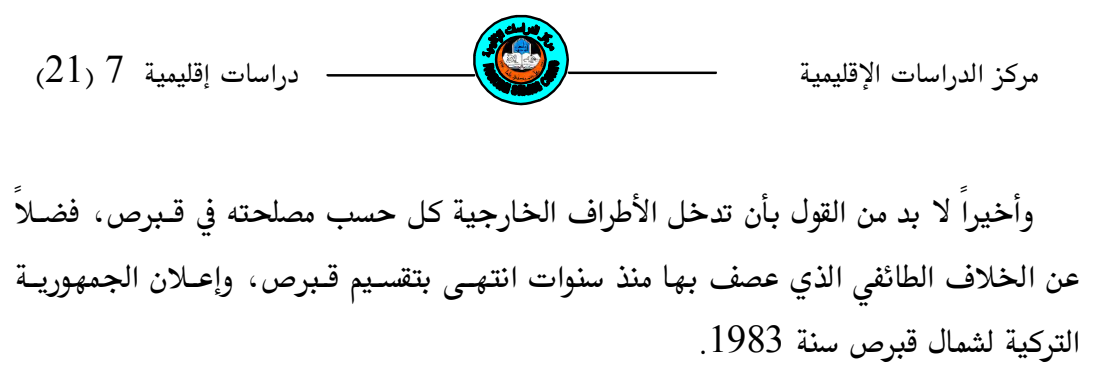

\title{
The Development of cyprus crisis (1967-1983)
}

\author{
Dr. banna Azoo Behnan \\ lectures-Regional Studies Center-Mosul Univessity
}

\begin{abstract}
The crisis of cyprus came out in the international theatre after the indepenence of cyprus in 1960 which included two sects Turkish and Greek Creek Cypriots The crisis has been complicated during 19631964) due to the declaration of the turkish goverment to intervence the island by force.
\end{abstract}




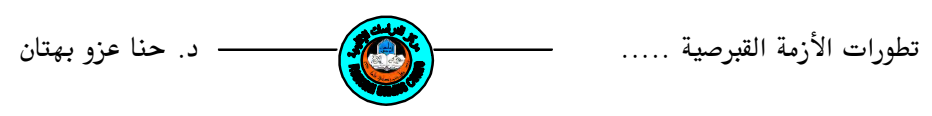

The crisis emerged again in 1967 because of violence acts between the two mentioned communities, and became more complicated as for the recent developments in which cyprus has been witnessed sinc mid of july 1974 till December 15, 1983, i.e. since the Greek military coup in cyprus and the Turkish military landing till the decleration of the Turkish Republic in north cyprus as an indepandert state.

$$
\text { الهوامش والمصادر }
$$

(1) Necati Ertekun, The Cyprus dispute and the Birth of the Turkish Republic of Northern Cyprus Oxford, 1984, p. 1.

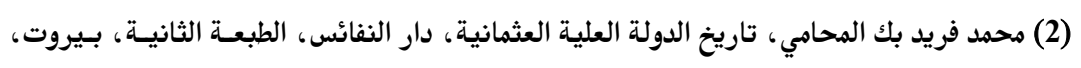

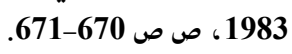

(3)Ertekun, Op. Cit, p. 1.

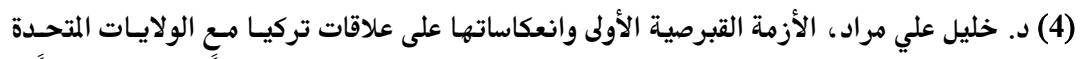

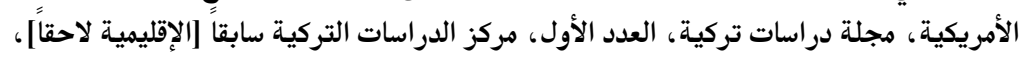

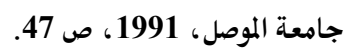

$$
\begin{aligned}
& \text { (5) نازلي معوض أحمد، الصراع التركي-اليوناني في الجزيرة القبرصية، مجلة السياسة الدولية، العدد }
\end{aligned}
$$

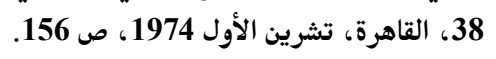

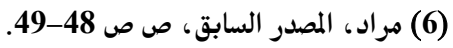

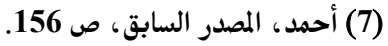

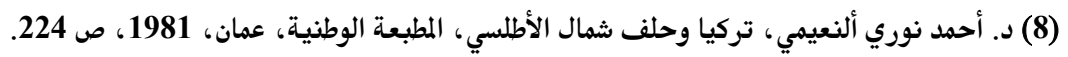

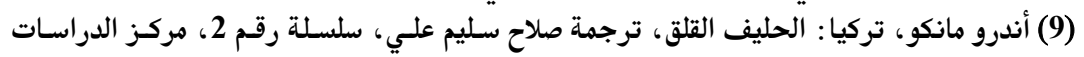

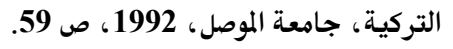

$$
\begin{aligned}
& \text { التر } \\
& \text { ينظر : د. نبيل حيدري، تركيا-دراسة في النيات السياسة الخارجية منذ 1945، 1948، صبر للطباعة والنشر، }
\end{aligned}
$$

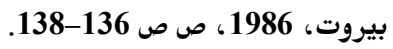

(11) Middle East Record, Published for the Shiloh Centre for Middle Eastern and Africa Studies, Jerusalem, 1971, pp. 526-527.

(12) I bid., pp. 527-528.

(13) Feros Ahmed, The Turkish experiment in demo curacy (1950-1974), London, West view Press, 1977, p. 415. 


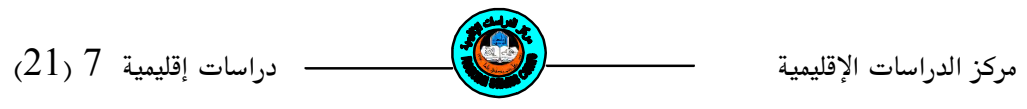

(14) I bid., p. 415.

(15) Ertekun, Op. Cit, p. 25.

(16) I bid., p. 25.

(17) I bid., p. 26.

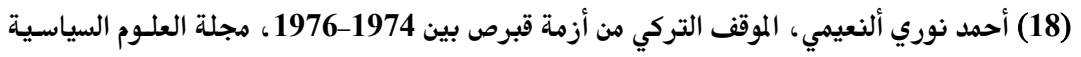

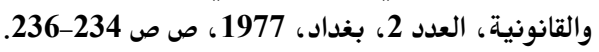

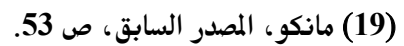

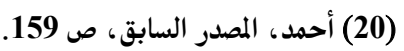

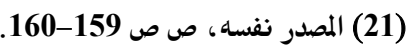

(22) Richard Clogg, Greece and the Cyprus Crisis, The World Today, Vol. 30, No. 9, London, 1974, p. 370.

(25) Clogg, Op. Cit, p. 370.

$$
\text { (23) ألنعيم، المصدر السابق، ص تركيا وحلف شمال الأطلسي، ص } 230 .
$$

$$
\begin{aligned}
& \text { (26) أحمد، المصدر السابق، ص ص 160 160-161. }
\end{aligned}
$$

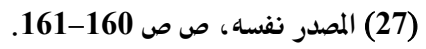

$$
\begin{aligned}
& \text { (28) مانكو، المصدر السابق، ص ص صل 53 54-54. }
\end{aligned}
$$

(29) The Middle East and North Africa (1984-1985), Europa Publications Limited, Thirty First edition, London. 1985, p. 717.

$$
\begin{aligned}
& \text { (31) النعيمي، تركيا وحلف شمال الأطلسي، ص } 231 \text { ، } 231 \text { ، }
\end{aligned}
$$

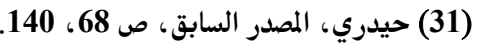

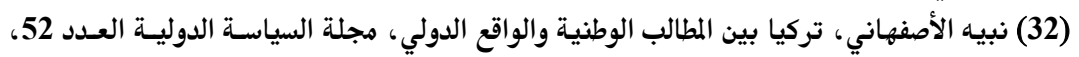

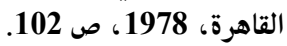

$$
\begin{aligned}
& \text { (33) المصدر نفسه، ص 102، صن } 102 .
\end{aligned}
$$

(34)The Middle East and North Africa, Op. Cit, p. 717.

$$
\begin{aligned}
& \text { (35) حيدري، المصدر السابق، ص } 140 .
\end{aligned}
$$

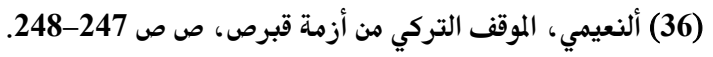

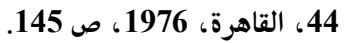

$$
\begin{aligned}
& \text { (38) ألنعيمي، تركيا وحلف شمال الأطلسي، ص } 1976 \text { ص } 243 .
\end{aligned}
$$

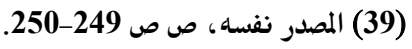

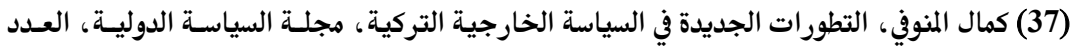



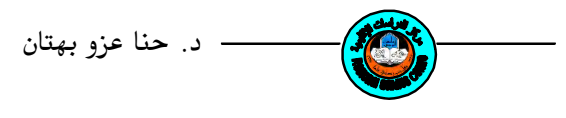

تطورات الأزمة القبرصية .......

$$
\begin{aligned}
& \text { (40) الأصفهاني، المصدر السابق، ص ص 99-100. }
\end{aligned}
$$

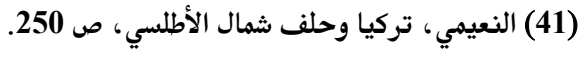

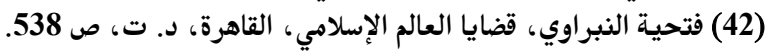

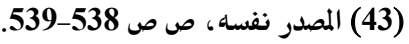

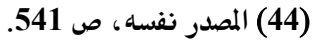

(45) John C. Campbell, Communist Strategies in the Mediterranean in: The Conduct of Soviet Foreign Policy, 2nd edition, Aldine Publishing Company, New York, 1988, p. 553.

(46) The Middle East and North Africa, Op. Cit, p. 717.

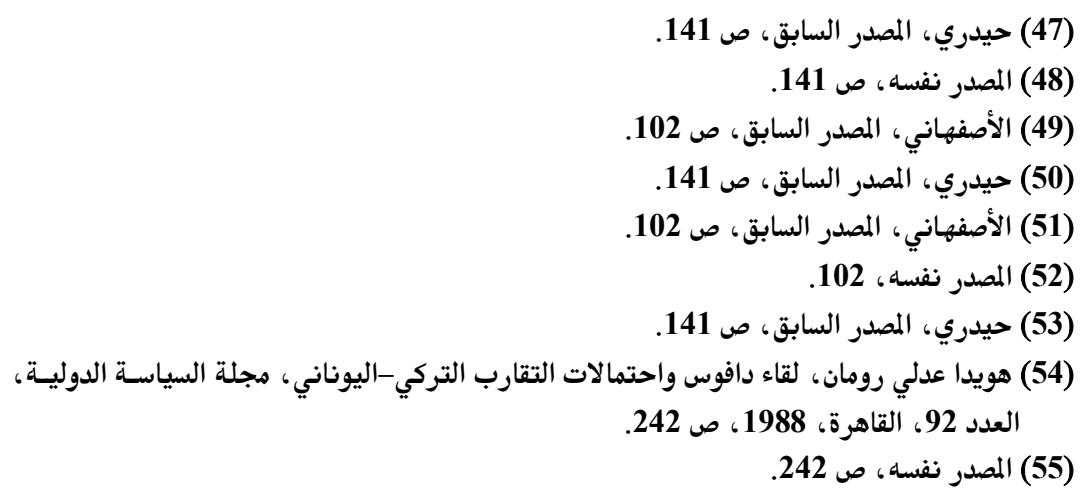

